\title{
Mild Cardiac Valve Regurgitation
}

National Cancer Institute

\section{Source}

National Cancer Institute. Mild Cardiac Valve Regurgitation. NCI Thesaurus. Code C99985.

Evidence of mild retrograde blood flow through the valve(s) of the heart. (ACC) 